\title{
Estrategias de enfrentamiento (Coping) de hijos que tienen la madre o el padre internado en una Unidad de Terapia Intensiva (UTI)*
}

\author{
Coping Strategies of Children who have a \\ Mother or Father in a Hospital intensive Care Unit (ICU)
}

\author{
Fernanda de Azevedo Lima** \\ Instituto Brasileiro de Gestão e Marketing \\ - Faculdade IBGM \\ Maria Cristina Lopes \\ de Almeida Amazonas \\ Universidade Católica de Pernambuco
}

Walfrido Nunes de Menezes

Universidade Federal de Pernambuco, UFPE, Brasil.

Recibido: 9 de agosto de 2011

Revisado: 31 de octubre de 2011 Aceptado: 12 de diciembre de 2011

\section{Resumen}

La presente investigación tuvo el objetivo de verificar las estrategias de enfrentamiento utilizadas por hijos que tienen la madre o el padre internado en una Unidad de Terapia Intensiva (UTI). Participaron 30 hijos, de ambos sexos, que contestaron a un cuestionario sociodemográfico y el inventario de estrategias de Coping de Folkman \& Lazarus (1985). El procedimiento de análisis del inventario fue: 1) Puntuación obtenida por el participante, en los ítems de cada factor correspondiente a las estrategias de enfrentamiento; 2) Cálculo de los coeficientes de correlación de Spearman, entre las 66 cuestiones del inventario y algunas variables como: religión, franja de edad, escolaridad y filiación. Existe correlación significativa positiva o negativa entre estas variables y algunos ítems del inventario, pero esto no es lo suficiente para afirmar que hay correlación entre las variables y determinadas estrategias. A pesar de que los participantes utilizaran todas las estrategias de enfrentamiento, las predominantes fueron: revaluación

Artigo derivado da Dissertação de Mestrado: Unidade de Terapia Intensiva: um estudo comtilhos que possuem a mãe ou o pai neste modo de internação, junto ao Programa de Pós Graduação em Psicologia Clinica da Universidade Católica de Pernambuco (UNICAP). Artículo producto de investigación. Núcleo de Pesquisas em Gestão de Recursos Humanos- NUPgrh na Faculdade IBGM.

** Correspondencia: Fernanda de Azevedo Lima, Instituto Brasileiro de Gestão e Marketing-Faculdade IBGM-R. Joaquim Felipo, 250, Soledade, Recife/PE, Cep:50050-340 Tel: (81) 3231-7771 / 5712 Correio eletrônico: nandamarina_psi@yahoo.com.br. Maria Cristina Lopes de Almeida Amazonas-Universidade Católica de Pernambuco-UNICAP. Estrada do Encanamento, 608, apto 1303, Casa Forte, Recife/PE, Cep: 50050-900. Correio eletrônico: crisamaz@gmail.com Tel: (81) 2119-4015 Fax: (81) 2119-4020. Walfrido Nunes de Menezes- Faculdade Integrada do RecifeEstácio/FIR. Av. Engenheiro Abdias de Carvalho, 1678, Recife/PE. Correio eletrônico: walfridomenezes@yahoo.com.br Tel: (81) 3226-8800. 
positiva (97\%); soporte social (93\%); y resolución de problemas (77\%). Estos datos corroboran los hallazgos de otras investigaciones sobre la temática y pueden subsidiar una práctica más efectiva del equipo de salud junto a esa populación.

Palabras clave: unidad de terapia intensiva, familia, enfermedad, stress, estrategias de enfrentamiento.

\section{Resumo}

Este estudo teve como objetivo verificar as estratégias de enfrentamento utilizadas por filhos que possuem a mãe ou o pai internado em uma Unidade de Terapia Intensiva (UTI). Participaram 30 filhos, de ambos os sexos, que responderam: Uma Ficha Sócio Demográfica e o Inventário de Estratégias de Coping de Folkman e Lazarus (1985). A análise das respostas no inventário se deu em dois momentos: 1) contagem da pontuação obtida por cada participante, nos itens de cada fator correspondente às estratégias de enfrentamento; 2) cálculo dos coeficientes de Correlação de Spearman entre as 66 questões do Inventário e algumas variáveis: Religião; Faixa etária, Escolaridade e Filiação. Foi verificada correlação significativa positiva ou negativa entre estas variáveis e alguns itens do inventário, porém isto não é o suficiente para afirmar que há correlação entre as variáveis e determinadas estratégias. Embora os participantes tenham usado todas as estratégias de enfrentamento, as que predominaram foram: Reavaliação Positiva (97\%); Suporte Social (93\%) e Resolução de Problemas (77\%). Estes resultados corroboram estudos já realizados sobre esta temática e podem subsidiar uma prática mais efetiva da equipe de saúde junto a essa população.

Palavras chave: unidade de terapia intensiva; família; doença; stress; estratégias de enfrentamento.

\section{Abstract}

This study aimed to examine the coping strategies used by children who have the mother or father admitted to an intensive care unit (ICU). 30 children of both sexes participated, they answerd theDemographic and Socio Sheet and Coping Strategies Inventory of Folkman and Lazarus (1985). The analysis of responses in the inventory took place in two stages: 1) counting the score of each participant, the items of each factor corresponding to the coping strategies. 2) calculation of Spearman correlation coefficients among the and some 66 issues of the inventory variables like: religion, age, education and filiation. There is a significant positive or negative correlation between these variables and some inventory items, but this is not enough to say that there is correlation between the variables specific and strategies. Although participants used all strategies, those that predominated were: positive reappraisal (97\%), social support (93\%) and problem solving $(77 \%)$. These results corroborate previous studies' findings on this topic and can support a more effective practice of the health team whit this population.

Keywords: Intensive Care Unit family disease stress coping strategies. 


\section{Introdução}

De acordo com Lucchesi, Macedo e Marco (2008), a Unidade de Terapia Intensiva (UTI) é um setor que oferece cuidados aos pacientes que apresentam instabilidade clínica grave, através de atenção constante e especializada. Seu ambiente frequentemente é avaliado como altamente estressante, tanto pelos pacientes, quanto pela equipe de saúde que atua na unidade.

A angústia, que emerge do contato mais próximo com o adoecer e com os riscos de morte do paciente, pode ser perturbadora e desorganizadora, também para o familiar do paciente. Para Ismael (2004), a hospitalização pode significar uma situação de crise para a família, o que causa uma ruptura no que é considerado normal na dinâmica familiar.

Segundo Pinho e Santos (2008), no caso do processo de internamento na UTI, pode haver a emergência de uma série de sinais e sintomas de desestabilização física e emocional.

Segundo Romano (1997), a família é um sistema intercomunicante. Sua função é fornecer alimento afetivo para manter a homeostasia psíquica dos seus componentes, princípio fundamental para manutenção do equilíbrio familiar (Osório, 1996).

No entanto, conforme ressalta Silva (2000), é preciso ter em mente que para a família cumprir seu papel, e dar suporte à situação vivenciada pelo paciente, ela também precisa de apoio em suas necessidades físicas e emocionais. A hospitalização de um de seus membros pode ser percebida como um evento estressor e o estresse psicológico é uma reação particular entre a pessoa e o ambiente, que é avaliada por ela como sobrecarregando ou excedendo seus recursos, colocando em risco seu bem-estar (Folkman \& Lazarus, 1984). Se a hospitalização for percebida desta forma, pode gerar uma desorganização do núcleo familiar, exigindo uma adaptação. A forma como os indivíduos enfrentam esses eventos estressores é chamada de coping, termo cujo correspondente em português é estratégias de enfrentamento.

\section{Família, Doença e Coping}

A palavra coping não possui tradução literal para o português, mas seu significado aproximado pode ser entendido como se ajustar, lidar ou enfrentar. De acordo com Folkman e Lazarus (1984), são considerados, como tal, os esforços cognitivos e comportamentais, que têm como objetivo lidar com demandas internas ou externas que surgem em situações de estresse e que o indivíduo avalia como algo que excede seus próprios recursos. Segundo estes autores, qualquer empenho em se lidar com o estressor é uma resposta de enfrentamento (coping), independentemente do sucesso ou fracasso que se tenha obtido.

Para Noyes (1999), o enfrentamento inclui estratégias adotadas pelo indivíduo para se adaptar a uma situação estressora. Cerqueira (2000) entende o coping como um processo com as seguintes características: o foco é o que as pessoas fazem ou pensam e não o que fariam; as estratégias se inserem em um contexto e não se pode generalizar.

$\mathrm{Na}$ literatura científica, já existem diversos estudos que examinam as estratégias de enfrentamento utilizadas diante do evento estressor: doença na família. De acordo com Chaves, Cade, Montovani, Oleite e Spire (2000) "o coping interfere mais no processo saúde-doença do que a existência ou não de stress e pesquisas têm buscado elucidar como o coping pode predispor ou desencadear doenças e interferir na evolução da mesma".

Rodrigues, Rosa, Moura e Batista (2000) investigaram o ajustamento emocional e as estratégias de coping em pais de crianças com doença de foro oncológico. Estes autores realizaram um estudo comparativo entre os pais de crianças com a doença e os pais de crianças recuperadas. A amostra foi composta por 60 indivíduos nos quais se aplicou o questionário Dealing With Illness. Os resultados mostraram diferenças significativas no uso de estratégias de enfrentamento entre os dois grupos. Uma dessas diferenças foi a de que a estratégia: "compreensão cognitiva positiva" foi 
utilizada somente pelos pais das crianças recuperadas. Estes achados foram interpretados como uma dificuldade dos pais, diante do diagnóstico da doença que traz consigo o choque e o medo do desconhecido. Para esses autores, esta seria uma fase de angústia e incerteza, o que impede que a cognição positiva da situação aconteça.

Oliveira (2004) avaliou as estratégias de enfrentamento (coping) de 50 familiares de pacientes internados em UTI Clínica e Unidade Coronária (UCO) do InCor-HCFMUSP, Brasil, utilizando o Inventário de Estratégias de Coping, de Folkman e Lazarus (1985), adaptado por Savóia, et ál. (1996). Observou-se que as estratégias mais utilizadas pelos familiares foram: reavaliação positiva (94\%), suporte social (88\%) e resolução de problemas $(84 \%)$. Estes resultados mostram que, num primeiro momento, eles recorrem ao suporte social e isto foi interpretado como uma forma de buscar compreensão, compartilhar as angústias e cuidados de outras pessoas para consigo, visando um bem estar emocional. Num segundo momento, buscam soluções para a situação recorrendo a aspectos positivos desta, o que leva a uma reavaliação e um enfrentamento do problema mais eficaz.

Kohlsdorf e Costa Junior (2008) investigaram estratégias de enfrentamento de pais de crianças que se encontram fazendo tratamento de câncer. Em tal trabalho houve uma revisão de literatura na área da psiconcologia pediátrica, destacando estudos e pesquisas relativos ao tema do enfrentamento da doença e do tratamento, publicados entre 1996 e 2007. Os resultados mostraram que uma das estratégias de enfrentamento mais utilizada foi a busca de suporte social e a busca de religiosidade e/ou pensamento fantasioso. 0 uso dessas estratégias pode reduzir os riscos de desordens uma vez que diminuem o impacto do estressor, no caso, a doença do familiar.

Colleto e Câmara (2009) avaliaram os tipos de estratégias de coping utilizadas por 40 cuidadores de crianças com doença crônica, usando o
Inventário de Estratégias de Coping de Folkman e Lazarus (1985) adaptado por Savóia, et ál. (1996). Constatou-se que uma das estratégias mais usadas foi a reavaliação positiva, ou seja, os cuidadores se apegam a qualquer sinal de melhora para manter a esperança e o pensamento positivo em relação às possibilidades de fazer frente à situação de doença da criança.

Analisando essas pesquisas, notaram-se convergências: as estratégias de enfrentamento: reavaliação positiva e suporte social são as mais utilizadas. No entanto, percebem-se, também, algumas lacunas: a maioria dos estudos sobre coping, família e doença privilegia investigar as estratégias de enfrentamento utilizadas pelos cuidadores pais. Uma exceção é o estudo de Oliveira (2004), que incluiu vários participantes: pais, cônjuges dos pacientes entre outros. Isto sugere a necessidade de se realizar estudos que foquem, de modo específico, outros graus de parentesco, por exemplo, os filhos dos pacientes.

Além disso, pesquisas com a temática coping e familiares de pacientes em UTI ainda são escassas e as que existem enfatizam, sobretudo, sentimentos e necessidades de alguns membros da família, mas não focam como eles enfrentam esta situação, principalmente quando se trata de um pai ou uma mãe que se encontra internado. Diante disso, são relevantes estudos desta natureza, uma vez que a identificação de tais estratégias poderia auxiliar na elaboração de programas de cuidados para esta população.

Considerando esse panorama, foram investigadas, neste estudo, as estratégias de enfrentamento utilizadas pelos filhos de pacientes internados em UTI, através de um Inventário de Estratégias de Coping. Foi realizada a correlação de Spearman para estudar a relação entre algumas características dos participantes (religião, idade, escolaridade, filiação - mãe ou pai internado na UTI) com as questões referentes às diferentes estratégias de coping. 


\section{Metodología}

\section{Participantes}

Participaram 30 filhos de pacientes internados em uma UTI de um hospital particular da cidade do Recife, Estado de Pernambuco, Nordeste do Brasil. Este é caracterizado como um HospitalUTI, e a maioria dos seus pacientes são idosos cardíacos graves e crônicos ou com problemas neurológicos decorrentes de trauma.

Do total de participantes, 3 eram homens e 27 eram mulheres, 7 estavam com o pai nesta unidade e 23 tinham a mãe neste modo de internação. 0 critério de inclusão na pesquisa foi: ter a mãe ou o pai internado na UTI há pelo menos 48 horas. A média de idade dos participantes foi de 44 anos, sendo a idade mínima de 20 e a máxima de 59 anos. Entre estes, 12 concluíram a graduação (ensino superior), 11 possuíam o $2^{\circ}$ grau completo (ensino médio), e 7 tinham somente o $1^{\circ}$ grau (ensino fundamental).

\section{Instrumentos}

Os instrumentos utilizados foram: uma Ficha Sociodemográfica, que incluía: dados referentes ao sexo, à idade, ao grau de escolaridade, à profissão e à religião; e o Inventário de Estratégias de Coping, de Folkman e Lazarus (1985), adaptado por Savóia, et ál. (1996).

Este instrumento é integrado por 66 itens que avaliam a maneira como as pessoas lidam com as demandas internas ou externas de um evento estressante específico. É composto por pensamentos e ações, podendo ser definida a intensidade do uso por meio de escalas: 0 (não utiliza), 1 (usei um pouco), 2 (usei bastante) e 3 (utiliza em grande quantidade).

Os itens do inventário foram divididos em oito fatores que indicam as seguintes estratégias de enfrentamento: confronto, afastamento, autocontrole, busca de suporte social, aceitação de responsabilidade, fuga e esquiva, planejamento e resolução de problemas, reavaliação positiva. Os participantes foram orientados a responder às questões, pensando especificamente no enfrentamento da situação de ter a mãe ou o pai internado em uma UTI.

\section{Procedimento de coletas de dados}

A pesquisa teve início após o projeto ter sido aprovado pelo Comitê de Ética em Pesquisa da Universidade Católica de Pernambuco (UNICAP), sob o protocolo $n^{\circ}$ CEP 033/2009 e obtida a permissão da diretoria do hospital.

Os participantes do estudo foram informados das finalidades e dos benefícios da pesquisa, do sigilo quanto às suas identidades e de que poderiam desistir da participação no momento em que desejassem sem sofrer nenhum tipo de prejuízo. Após o que, assinaram o Termo de Consentimento Livre e Esclarecido.

Logo após a assinatura, foi entregue a eles uma Ficha Sociodemográfica para responderem e o Inventário de Estratégias de Coping, de Folkman e Lazarus (1985), adaptado por Savóia, et ál. (1996). A aplicação do questionário ocorreu de forma individual e em um local apropriado, isto é, em um recinto privado do próprio hospital.

Também foi parte integrante da pesquisa oferecer um retorno a todos os participantes e um atendimento psicológico breve àqueles que se mostraram necessitados ou que solicitaram algum outro encontro individual para uma orientação mais específica.

\section{Procedimento de Análise dos dados}

Para realizar a análise dos dados do Inventário de Estratégias de Coping, de Folkman e Lazarus (1985), adaptado por Savóia et al (1996), utilizaram-se as orientações dos próprios autores, ressaltando que para aferir os resultados da aplicação, os itens marcados devem ser somados pelos participantes, em cada fator, que corresponde a um determinado tipo de estratégia. Para estabelecer um melhor entendimento desses resulta- 
dos, eles foram quantificados e apresentados em porcentagens em forma de tabela.

$\mathrm{Na}$ sequência, foram calculados os coeficientes de correlação entre as variáveis de interesse (religião, faixa etária, escolaridade e filiação-mãe ou pai internados na UTI) e as 66 questões do inventário. No caso de variáveis medidas através de escores, a literatura consultada sugere que é melhor optar pelo cálculo do Coeficiente de Correlação de Spearman, que é não paramétrico, ao invés do Coeficiente de Correlação de Pearson (Spiegel, 1993). Nessa análise, foi utilizado o software SPSS (Statistical Package for the Social Sciences), versão 17.0.

\section{Análise e Discussão dos resultados}

Quando se constrói um inventário para verificar a percepção das pessoas sobre qualquer proble$\mathrm{ma}$, o que se pretende é ter a certeza de que as medições refletem com precisão os resultados do inventário e que estão livres de erros aleatórios. Quando há erros aleatórios, o resultado observado é menos confiável para estimar o valor verdadeiro das medições. A forma mais usada para medir a estimativa da confiabilidade de um inventário é a Consistência Interna. Esta por sua vez pode ser calculada pelo Alfa de Cronbach.

A estimativa da confiabilidade através do Alfa de Cronbach demonstra o grau em que os itens do questionário estão inter-relacionados. Quando a diferença é pequena, não é possível identificar se ela é real ou é devida a algum erro existente na formulação ou entendimento da questão (Hayes, 2001).

O Alfa de Cronbach pode variar de 0 a 1, em que 1 demonstra presença de consistência interna de $100 \%$ e zero significa a ausência total de consistência entre os itens.

$\mathrm{Na}$ aferição da validade interna da escala, Inventário de Estratégias de Coping, de Folkman e Lazarus (1985), adaptado por Savóia, et ál. (1996), observou-se que este instrumento apresenta coerência interna, uma vez que indicou um $a=0,767$. Isto revela uma razoável consistência interna da escala. Aferimos tal consistência pelo coeficiente Alpha de Cronbach, calculado para os itens em sua totalidade.

Considera-se que valores de Alpha superiores a 0,7 são suficientes para garantir a confiabilidade da escala. Segundo Pestana e Gageiro (2005), caso o Alpha seja negativo, há correlações negativas, o que viola o modelo de consistência interna e inviabiliza o seu uso.

\section{Estratégias de Enfrentamento}

Do tratamento dos dados coletados através do Inventário de Estratégias de Coping, de Folkman e Lazarus (1985), obtiveram-se as estratégias de enfrentamento mais utilizadas pelos filhos dos pacientes em UTI. Após a soma dos itens: não utiliza, utiliza algumas vezes, utiliza grande parte das vezes e utiliza quase sempre, verificou-se que os participantes recorreram a todas as estratégias em diferentes graus de intensidade. Das oito estratégias existentes, seis alcançaram um percentual acima de $60 \%$ de utilização, no entanto, três predominaram: Reavaliação Positiva (97\%); Suporte Social (93\%) e Resolução de Problemas (77\%), conforme apresentado na tabela a seguir:

Tabela 1.

Estratégias de Enfrentamento utilizadas com maior frequência

\begin{tabular}{lll}
\hline \multicolumn{1}{c}{ Estratégias } & N & $\%$ \\
\hline Reavaliação Positiva & 29 & 97 \\
Suporte Social & 28 & 93 \\
Resolução de Problemas & 23 & 77 \\
Fuga e Esquiva & 21 & 70 \\
\hline Autocontrole & 19 & 63 \\
Aceitação da Responsabilidade & 18 & 60 \\
Confronto & 7 & 23 \\
Afastamento & 1 & 3 \\
\hline
\end{tabular}

Estes dados corroboram os achados de Oliveira (2004), em uma pesquisa sobre coping e UTI, em que foi verificado que os familiares de pacientes utilizavam, predominantemente, estas mesmas 
estratégias: Reavaliação Positiva (94\%); Suporte Social (88\%); e Resolução de Problemas (84\%). Isto leva a crer que o contexto é muito importante na busca de estratégias de enfrentamento. No entanto, outros fatores, tais como as diferenças individuais, o grau de parentesco, a gravidade da doença, a idade do paciente, entre outros, também têm um peso sobre como as pessoas enfrentam a situação.

A Reavaliação Positiva é uma estratégia cuja emissão depende mais de recursos da própria pessoa. Para Savóia (2000), com a finalidade de amenizar a gravidade da situação, o indivíduo busca se concentrar nos aspectos positivos dela; assim a carga emotiva do acontecimento pode ser amenizada o que permite reavaliar a situação como um todo. Resultado semelhante foi encontrado nos estudos de Colleto e Câmara (2009). Neste, uma das estratégias mais utilizadas pelos cuidadores de crianças com doenças crônicas foi a reavaliação positiva, e o uso dessa estratégia fazia com que esses participantes apresentassem esperança em relação às possibilidades de cura de seu ente querido.

Considerando a UTI como um ambiente impessoal e que ativa sentimentos de sofrimento e de perda, compreende-se que a família do paciente experimente reações de angústia ante essa situação. É contra esta dor que a família reage. Assim, podemos considerar que nossos participantes utilizaram a Reavaliação Positiva, como forma de amenizar tal aflição, tão presente no cenário das UTIs.

Eles lançaram mão, ainda, do Suporte Social. Segundo Senna e Antunes (2004), esta estratégia está relacionada a qualquer informação, auxílio material ou afetivo oferecido por grupos ou pessoas mais próximas do paciente e seu familiar. Segundo Bousso e Angelo (2001), a família do paciente em UTI utiliza esta estratégia para não desanimar. Para estes autores, é essencial a ajuda que a família recebe de outros parentes, amigos e outras famílias, no sentido de ir transformando a definição de UTI como sendo um lugar para morrer. Este suporte social dá esperança e deixa os familiares fortalecidos. As respostas de Apoio Social encontradas por Folkman e Lazarus (1984) foram agrupadas e incluem os itens: "procurei um amigo para pedir conselho," "falei com alguém sobre como estava;" "conversei com outra pessoa sobre o ...;" "falei com alguém que poderia fazer...;" "aceitei a simpatia e a compreensão;" "procurei ajuda profissional." Todas estas respostas foram apontadas por nossos participantes e têm um ponto em comum: envolvem outra pessoa na sua emissão. São respostas que implicam alguma forma de estimulação social.

Conforme aponta Brown (1974), o suporte social pode reduzir os riscos do indivíduo se desorganizar ao se sentir amparado, tendo com quem falar e desabafar, o que reduz o impacto do estressor. Isto se refere a um enfrentamento centrado na emoção, pois serve como alívio e regulação do estado afetivo. Segundo Folkman e Lazarus (1984), há dois tipos principais de estratégias: coping centrado no problema e coping centrado na emoção. 0 primeiro consiste em dirigir esforços no sentido de mudar a situação que deu origem ao mal estar. 0 segundo tipo representa esforços no sentido de regular o estado emocional em episódios estressantes. Neste segundo caso, essa pessoa, que funciona como um sistema de apoio pode ser envolvida no tratamento e se tornar um elemento importante, tanto como mais um cuidador do paciente, como também ser aquela que repassa as informações para o parente que apresenta dificuldade de interpretação devido à ansiedade, depressão ou outro sentimento que prejudique a cognição.

Segundo Nunes (2004), vale ressaltar que o psicólogo hospitalar se torna um elo adequado para trabalhar a minimização desses sentimentos acima citados e a angústia dos familiares dos pacientes, pois ele se coloca como um facilitador da relação: família-equipe. Além de viabilizar as informações necessárias entre os diversos elos na unidade (família, paciente e equipe médica), favorece o apoio psicológico a esses grupos, gerando uma melhora da comunicação entre eles. Além disso, o psicólogo é o profissional que está preparado para escutar a família.

A terceira estratégia mais utilizada foi Resolução de Problemas. Na tentativa de lidar com a si- 
tuação de ter o pai ou a mãe na UTI, os filhos buscaram amenizar a circunstância através de planos de ação. Esta situação faz com que os envolvidos mudem seus hábitos, a fim de permanecer a maior parte do tempo acompanhando a evolução do tratamento de seu parente no hospital. Este resultado corrobora com os achados de Barros, Menandro e Trindade (2006), cujo estudo trata da experiência de homens que têm um filho na UTINeonatal. Esses autores ressaltam que uma pessoa que tem um familiar internado em uma UTI busca se adaptar à nova situação reorganizando suas atividades cotidianas. Imaginar que tais atividades estão preestabelecidas pode reduzir a tensão emocional do indivíduo, o stress e evitar o aparecimento de futuras doenças.

Nota-se, ainda, a dificuldade que alguns filhos têm de lidar com essa situação, uma vez que a estratégia Fuga e Esquiva também foi utilizada por um grande percentual dos filhos (70\%). Desejos como: "Espero que um milagre aconteça" e "Desejei que de alguma forma a situação acabasse" foram assinalados. De acordo com Oliveira (2004), pode-se pensar que a utilização da fuga pode estar relacionada à complexidade de ter um familiar na UTI e o sofrimento que isto acarreta. Segundo Fortune, et ál. (2003), o coping evitativo tende a manter a desordem emocional e a utilização de estratégias de evitação; no estudo desses pesquisadores, está associado positivamente a altos escores de ansiedade.

Vale salientar, também, que a estratégia de afastamento pode demonstrar ainda a dificuldade que o indivíduo tem de lidar com a possibilidade de morte. Trask, et ál. (2003) denominam como estratégias mal-adaptativas os comportamentos de esquiva e fuga, e pesquisas realizadas por estes autores apontaram maiores indicadores de sofrimento, quando tais estratégias foram adotadas.

A estratégia de Autocontrole também foi usada (63\%). O item mais assinalado foi: "Procurei não fazer nada apressadamente ou seguir meu primeiro impulso". Esse achado corrobora o que diz a literatura: segundo Oliveira (2004), os familiares de pacientes internados em UTI sentem a necessidade de transmitir aspectos positivos ao paciente. Para favorecer sua melhora, tendem a controlar suas emoções, para que possam buscar soluções para a situação. Silva, Muller e Bonamigo (2006), concordam com o que diz Oliveira (2004) e acrescentam que um dos motivos para que alguns filhos utilizem essa estratégia pode ser o fato de não quererem demonstrar desespero diante do paciente.

De acordo com Oliveira (2004), o coping Aceitação da Responsabilidade pode apontar sentimentos de culpa e de responsabilidade. Apesar de a internação dos pais de nossos participantes na UTI ter sido em consequência de doenças orgânicas, dezoito dos trinta se percebiam responsáveis pelo adoecimento e internação de seu pai/mãe. Esta situação pode mobilizar nos filhos sentimentos de autocrítica e de autorrepreensão devido a erros que podem ter cometido no passado. Nesse sentido, eles podem realizar ações para reparar os danos enquanto utilizam a estratégia de Aceitação da Responsabilidade.

Uma estratégia pouco usada nesses participantes foi a de Confronto e Afastamento (23\% e 3\%, respectivamente). Alguns comportamentos que demonstram o confronto com a situação são: agressividade e impulsividade. Segundo Shimizu e Ciampone (2002) os familiares de pacientes em UTI podem passar por um dos estágios ressaltados por Kubler-Ross, como a raiva e a revolta, mas essas podem ser substituídas pela aceitação da situação. Vale salientar que a rotina de uma UTI provoca uma ruptura na relação entre o paciente e sua família, alimentando a ideia de perda iminente. Diante disso, é provável que os filhos do paciente evitem situações que gerem agressividade, conflitos e tensões, concentrando-se apenas no que for o melhor para o paciente. No que tange ao coping Afastamento, pode-se supor que a mesma sensação de perda iminente leve ao desejo de permanecer perto do ente querido e enfrentar a circunstância, o que pode justificar o pouco uso da estratégia Afastamento. Resultados semelhantes foram encontrados no estudo de Faria (2002). Neste, os familiares também não negaram ou recusaram ter contato com o fato desestruturante: ter um parente na UTI. 
Correlação significativa entre características dos participantes e alternativas das estratégias de coping

Nesta parte da análise, foi usada a correlação de Spearman para estudar a relação entre as características dos participantes (religião, idade, escolaridade, filiação - mãe ou pai internado na UTI) com as questões referentes às diferentes estratégias. O coeficiente de Spearman é um teste não paramétrico, que mede a intensidade da relação entre variáveis ordinais. Este teste não é sensível a assimetrias na distribuição, nem à presença de outliers, não exigindo que os dados provenham de populações normais. Varia entre -1 e 1 e quanto mais próximo estiver destes extremos, mais intensa será a associação entre as variáveis (Spiegel,1993). A significância adotada foi de $5 \%$.

Diante disso, esta parte do trabalho foi dividida em duas etapas: primeiramente foram cruzadas todas as questões do Inventário (66) com as variáveis selecionadas, a saber: religião, idade, escolaridade, filiação - mãe ou pai internado na UTI. $\mathrm{Na}$ segunda etapa, selecionaram-se apenas as correlações significativas ( $p$-value $\leq 0,05$ ). A seguir, estes resultados serão apresentados.

Vale salientar que IEC = Inventário de Estratégias de Coping. Ao lado da sigla, encontra-se o número da questão do Inventário.

Tabela 1.

Coeficiente de Correlação de Spearman entre religião e questões do Inventário de Coping

\begin{tabular}{ll}
\hline Variáveis & Resultados \\
\hline Religião x IEC-51 (Pro- & $r_{s}=-0,412$ \\
meti a mim mesmo que & $p$-value $=0,024$ \\
as coisas seriam dife- & Relação significativa nega- \\
rentes da próxima vez). & tiva \\
\hline
\end{tabular}

No quadro 1, pode-se perceber que houve uma correlação significativa negativa entre religião e a questão $51(p=0,024) .0 r_{s<0}$ indica que os filhos ateus/agnósticos utilizam esta alternativa em grande quantidade, o que não ocorre com os que possuem religião. Segundo Silva e Moreno (2004), os familiares reagem de formas diversas ao processo de adoecimento, de acordo com o entendimento que estes possuem acerca da religião.

De acordo com Batista (2004), a internação em uma Unidade de Terapia Intensiva ocorre, na maioria das vezes, de forma súbita, como sinônimo de agravamento de risco iminente gerando conflitos emocionais frente à angústia de morrer. Nesta situação é comum emergir no homem a espiritualidade e religiosidade. Isto amenizaria a ansiedade e sofrimento diante da situação de adoecimento.

As pessoas religiosas utilizam diversos elementos de distintas crenças. Surgem construções da doença enquanto mal espiritual, decorrentes de obrigações não cumpridas, desavenças afetivas, karma ou destino. Diante disso, é a religião que permitirá ao familiar, pelo exercício da fé, a possibilidade da doença e da cura. Das cinco questões relacionadas à Aceitação de Responsabilidade, apenas esta apresentou correlação significativa com a Religião.

Tabela 2.

Coeficientes de Correlação de Spearman entre faixa etária e questões do Inventário de Coping

\begin{tabular}{ll}
\hline Variáveis & Resultados \\
\hline Faixa Etária x IEC-14 (Procurei & $\mathrm{r}_{\mathrm{s}}=0,498$ \\
guardar para mim mesmo(a) & $\begin{array}{l}p \text {-value }=0,005 \\
\text { os meus sentimentos). }\end{array}$ \\
& $\begin{array}{l}\text { Relação significativa } \\
\text { positiva }\end{array}$ \\
\hline Faixa Etária x IEC-31 (Falei & $\mathrm{r}_{\mathrm{s}}=-0,368$ \\
com alguém que poderia fa- & $p$-value $=0,046$ \\
zer alguma coisa concreta & Relação significativa \\
sobre o problema). & negativa \\
\hline
\end{tabular}

No referente à correlação entre faixa etária dos filhos e as questões do inventário, percebeu-se que houve uma correlação significativa positiva com a questão 14 ( $p=0,005)$. $0 r_{s}, 0$ aponta que a faixa etária que compreende idade maior de 50 anos teve correlação com a alternativa: "Procurei guardar para mim mesmo (a) os meus sentimentos." Segundo Papalia (2006), pessoas de idades diferentes interpretam os problemas de forma distinta e identificam tipos diferentes de 
soluções como efetivas. Adultos de meia-idade, assim como os mais velhos, tendem a utilizar estratégias diferentes das dos adultos mais jovens. $\mathrm{Na}$ meia-idade, as pessoas direcionam sua preocupação ao eu interior e, comparadas com pessoas mais jovens, muitas pessoas de meia-idade ou mais velhas têm pouco tempo e pouca energia para conversar com amigos. Este item está relacionado à estratégia de Autocontrole. Além disso, vale salientar que "guardar os sentimentos para si" pode ser uma forma de poupar o paciente que está internado na UTI.

Houve, também, uma correlação significativa negativa com a questão 31 (Falei com alguém que poderia fazer alguma coisa concreta sobre o problema, $p=0,046)$, que está relacionada à estratégia Suporte Social. $0 r_{s}<0$ indica que quanto maior for a faixa etária, menos é dado este tipo de resposta. De acordo com Papalia (2006), para o adulto jovem, o apoio emocional dos amigos pode ajudar a minimizar o estresse ou a angústia.

Tabela 3.

Coeficientes de Correlação de Spearman entre escolaridade e questões do Inventário de Coping

\begin{tabular}{|c|c|}
\hline Variáveis & Resultados \\
\hline $\begin{array}{l}\text { Escolaridade x IEC-2 } \\
\text { (Tentei analisar o pro- } \\
\text { blema para entendê-lo } \\
\text { melhor). }\end{array}$ & $\begin{array}{l}r_{s}=0,416 \\
p \text {-value }=0,022 \\
\text { Relação significativa po- } \\
\text { sitiva }\end{array}$ \\
\hline $\begin{array}{l}\text { Escolaridadade } x \text { IEC- } 25 \\
\text { (Desculpei ou fiz alguma } \\
\text { coisa para repor os da- } \\
\text { nos). }\end{array}$ & $\begin{array}{l}r_{s}=-0,411 \\
p \text {-value }=0,024 \\
\text { Relação significativa ne- } \\
\text { gativa }\end{array}$ \\
\hline $\begin{array}{l}\text { Escolaridade x IEC-32 } \\
\text { (Tentei descansar, tirar } \\
\text { férias, a fim de esquecer } \\
\text { o problema). }\end{array}$ & $\begin{array}{l}r_{s}=-0,380 \\
p \text {-value }=0,005 \\
\text { Relação significativa ne- } \\
\text { gativa }\end{array}$ \\
\hline $\begin{array}{l}\text { Escolaridade } x \text { IEC- } \\
\text { 61(Preparei-me para o } \\
\text { pior). }\end{array}$ & $\begin{array}{l}r_{s}=0,486 \\
p \text {-value }=0,006 \\
\text { Relação significativa po- } \\
\text { sitiva }\end{array}$ \\
\hline
\end{tabular}

No Tabela 3, pode-se observar que houve uma correlação significativa positiva entre o grau de escolaridade dos filhos e as questões 2 (Tentei analisar o problema para entendê-lo melhor, $\mathrm{p}=$ 0,022) e 61 (Preparei-me para o pior, $p=0,006$ ). A primeira destas questões está relacionada à estratégia Resolução de Problemas, e a segunda à Aceitação da Responsabilidade. $0 \mathrm{r}_{\mathrm{s}}, 0$ ressalta a associação entre filhos que possuem o $3^{\circ}$ grau completo e estas alternativas.

Ocorreu, ainda, uma correlação significativa negativa com as questões 25 (Desculpei ou fiz alguma coisa para repor os danos, $p=0,024$ ) e 32 (Tentei descansar, tirar férias, a fim de esquecer o problema, $p=0,005)$. $0 r_{s<} 0$ aponta a associação entre filhos com grau de escolaridade menor e tais alternativas. As questões 25 e 32 estão relacionadas à estratégia Fuga e Esquiva.

Estes resultados indicam que os filhos que possuíam o ensino superior completo apresentaram formas diferenciadas de lidar com a situação (ter a mãe ou o pai na UTI), comparados com os filhos que tinham um grau de escolaridade menor. Segundo Foss, Vale e Speciali (2005), a educação, representada pelo total de anos de escolaridade, é uma variável que gera diferenças nas estratégias cognitivas empregadas.

Tabela 4.

Coeficientes de Correlação de Spear-man entre filiação e questões do Inventário de Coping

\begin{tabular}{|c|c|}
\hline Variáveis & Resultados \\
\hline $\begin{array}{l}\text { Filiação x IEC-2 (Tentei } \\
\text { analisar o problema para } \\
\text { entendê-lo melhor). }\end{array}$ & $\begin{array}{l}r_{s}=0,380 \\
p \text {-value }=0,038 \\
\text { Relação significativa po- } \\
\text { sitiva }\end{array}$ \\
\hline $\begin{array}{l}\text { Filiação x IEC-3 (Procurei } \\
\text { trabalhar ou fazer algu- } \\
\text { ma atividade para me } \\
\text { distrair). }\end{array}$ & $\begin{array}{l}r_{s}=0,413 \\
p \text {-value }=0,023 \\
\text { Relação significativa po- } \\
\text { sitiva }\end{array}$ \\
\hline $\begin{array}{l}\text { Filiação x IEC-12 (Concor- } \\
\text { dei com o fato, aceitei } \\
\text { meu destino). }\end{array}$ & $\begin{array}{l}r_{s}=0,409 \\
p \text {-value }=0,025 \\
\text { Relação significativa po- } \\
\text { sitiva }\end{array}$ \\
\hline $\begin{array}{l}\text { Filiação x IEC-25 (Descul- } \\
\text { pei ou fiz alguma coisa } \\
\text { para repor os danos). }\end{array}$ & $\begin{array}{l}r_{s}=0,395 \\
p \text {-value }=0,031 \\
\text { Relação significativa po- } \\
\text { sitiva }\end{array}$ \\
\hline
\end{tabular}




\begin{tabular}{|c|c|}
\hline Variáveis & Resultados \\
\hline $\begin{array}{l}\text { Filiação x IEC-27 (Tirei } \\
\text { o melhor da situação, o } \\
\text { que não era esperado). }\end{array}$ & $\begin{array}{l}r_{s}=0,362 \\
p \text {-value }=0,050 \\
\text { Relação significativa po- } \\
\text { sitiva }\end{array}$ \\
\hline $\begin{array}{l}\text { Filiação } x \text { IEC-34 (En- } \\
\text { frentei como um grande } \\
\text { desafio, fiz algo muito } \\
\text { arriscado). }\end{array}$ & $\begin{array}{l}r_{s}=0,603 \\
p \text {-value }<0,001 \\
\text { Relação significativa po- } \\
\text { sitiva }\end{array}$ \\
\hline $\begin{array}{l}\text { Filiação x IEC-35 (Procu- } \\
\text { rei não fazer nada apres- } \\
\text { sadamente ou seguir o } \\
\text { meu primeiro impulso). }\end{array}$ & $\begin{array}{l}r_{s}=0,630 \\
p \text {-value }<0,001 \\
\text { Relação significativa po- } \\
\text { sitiva }\end{array}$ \\
\hline $\begin{array}{l}\text { Filiação } x \text { IEC-39 (Mo- } \\
\text { difiquei aspectos da si- } \\
\text { tuação para que tudo } \\
\text { desse certo no final). }\end{array}$ & $\begin{array}{l}r_{s}=0,427 \\
p \text {-value }=0,019 \\
\text { Relação significativa po- } \\
\text { sitiva }\end{array}$ \\
\hline
\end{tabular}

No quadro 4, podem-se perceber as questões que apresentaram uma correlação significativa positiva com a variável filiação. Os $r_{s}>0$ apontam associação entre filhos que estavam com a mãe internada na UTI e as questões acima citadas. Estas questões estão relacionadas às estratégias: Aceitação da responsabilidade; Confronto; Autocontrole e Reavaliação Positiva. Não houve correlação entre filhos com pai na UTI e questões do inventário. Segundo Mackey (1985), ainda que possam ter acontecido algumas mudanças discretas no papel do pai no decorrer dos anos (ruptura da paternidade tradicional: pai tendo a função de provedor), comparadas com a mãe, ele continua a ter uma função de menor envolvimento emocional com os filhos, o que pode fazer com que estes sintam necessidade de lançar mão de um maior número de estratégias de enfrentamento, quando é a mãe que se encontra internada.

Um estudo realizado por Wallau, et ál. (2006) constatou algumas preocupações de filhos que possuíam a mãe em uma UTI. Os principais incômodos ressaltados foram: o estado geral da paciente e a insatisfação com as informações médicas prestadas. 0 que contribuía para um maior sofrimento diante da situação de ter a mãe internada em uma UTI.

\section{Considerações Finais}

Observa-se, neste estudo, que embora os participantes tenham usado todas as estratégias de enfrentamento, as que predominaram corroboram os achados de outros estudos: Reavaliação Positiva, Suporte Social e Resolução de Problemas. Isto aponta que eles estão lidando com a situação, buscando reagir e se reorganizar, pois estas estratégias tendem a reduzir a aflição, os riscos de desordens e as tensões emocionais.

Apesar de ter sido encontrada correlação significativa entre algumas variáveis, tais como, religião, faixa etária, escolaridade, filiação (pai ou mãe na UTI) e algumas questões do inventário, não é possível afirmar que exista correlação entre essas variáveis e as estratégias de enfrentamento que as questões representam, quer seja positiva ou negativa. Isto porque cada estratégia é avaliada através de no mínimo quatro itens ou questões e, no caso desta pesquisa, apenas uma questão ou item em cada estratégia alcançou correlação significativa com alguma dessas variáveis.

Um dado a ser ressaltado é o de que, ao tratar da correlação entre a variável Filiação e alguns itens do inventário $(2,3,12,25,27,34,35$ e 39) a correlação significativa positiva observada ocorreu entre os filhos que tinham a mãe, e não o pai, internada na UTI, o que indica que existem diferenças entre ter uma mãe ou um pai internados em uma UTI. É possivel supor que isto se deve ao estabelecimento mais forte de vínculos mãe $x$ filho/a existentes em nossa sociedade. Porém, nossos dados não foram conclusivos a esse respeito. Desse modo, seria importante estudos que comparassem as estratégias de enfrentamento utilizadas por filhos quando estes possuem a mãe em uma UTI, com outro grupo de filhos que possuem o pai neste modo de internação. Essas pesquisas contribuiriam para lançar mais luz sobre esta questão. 
Diante do exposto, vale ressaltar que Programas de Qualidade de Vida dos Familiares de pacientes internados em UTI devem ser parte integrante da cultura das organizações hospitalares. Em tais programas, poderiam ser abordadas as diversas estratégias de enfrentamento que contribuem para a promoção da saúde mental do familiar, o que, provavelmente, favoreceria a melhora do bem-estar geral do paciente e ajudaria em uma possível recuperação. Destaque-se aqui a importância do psicólogo hospitalar nestas intervenções, uma vez que este profissional é o mais habilitado para escutar e acolher a família que se encontra fragilizada e ansiosa com tal situação.

Assim sendo, cabe às instituições e aos psicólogos considerarem a importância de um local que possibilite um espaço de fala, escuta e troca de experiências entre esses familiares. Neste contexto, as famílias poderão, ainda, falar e desmistificar suas fantasias e tirar dúvidas referentes ao cenário da UTI.

Como limitações do estudo ressaltam-se o número reduzido de participantes. Vale salientar que não foi possível ampliar o número da amostra devido a pouca disponibilidade dos filhos, uma vez que boa parte deles tem dificuldade de permanecer mais tempo no hospital, em virtude de compromissos profissionais ou pessoais. Além disso, se faz mister levar em conta as próprias características do hospital que só permite visitas por períodos limitados. Diante disso, o familiar privilegia o contato com o paciente em detrimento à concessão de uma entrevista.

Almeja-se que este trabalho incentive a produção de mais pesquisas, envolvendo esta população, uma vez que o estudo não é conclusivo. Sugerese, por exemplo, pesquisas que comparem a experiência de filhos que possuem a mãe ou o pai no fim do ciclo vital internado em uma UTI com filhos que possuem o pai ou a mãe mais jovem internados nesta unidade. Recomenda-se, nesse sentido, a realização de pesquisas qualitativas junto a essa população. Estudos com esta perspectiva complementariam a visão sobre este fenômeno, uma vez que há poucas publicações a este respeito.

\section{Referências}

Barros, S. M. M., Menandro, P.R. M., Trindade, Z. A. (2006). Vivências paternas em UTI neonatal. Psicol. Hosp. V. 4 n. 2 São Paulo, Agosto. Recuperado em 24 de julho de 2011 de: http: / / pepsic. bvsalud.org/scielo. php?pid=S1677$74092006000200003 \& \mathrm{script}=\mathrm{sci}$ arttext\&tlng=pt

Batista, M. A. (2004). Presença do sagrado em um momento crítico: internação em uma Unidade de Terapia Intensiva. Rev. Brasileira de Enfermagem, 57, Brasília, Setembro/ Outubro. Recuperado em 28 de dezembro de 2011 de: http://www.scielo.br/scielo. php?pid=S003471672004000500013\&script=s ci_arttext\&tlng=pt

Bousso, R. S., Angelo, M. (2001). Buscando preservar a integridade da unidade familiar: a família vivendo a experiência de ter um filho na UTI. Rev. Esc. Enfermagem USP, 35(2), São Paulo, Junho. Recuperado em 24 de julho de 2011 de: http://www.scielo.br/pdf/ reeusp/v35n2/v35n2a11.pdf

Brown, G. W. (1974). Meaning, Measurement, and stress of life events.In. B.S., Dohrevend; B.P., Dohrevend. Stressful life events: Their Nature and Effects (217-243). New York.

Cerqueira, R. S. A. R. (2000). 0 conceito e metodologia de coping: existe consenso e necessidade? In: R.R. Kerbauy (Eds). Sobre o comportamento e cognição: conceitos, pesquisa e aplicação, a ênfase no ensinar, na emoção e no questionamento clínico (pp. 279-289). São Paulo: Ayrbytes.

Chaves, E. C., Cade, N. V., Montovani, M. F., Leite, R. C. B. O., Spire, W.C. (2000). Coping: significados, interferência no processo saúde-doença e relevância para a enfermagem. Rev. Esc. Enferm. USP, 34(4), São Paulo Dez. Recuperado em 30 de dezembro de 2011 de http://www.scielo.br/scielo.php?script=sci_ 
arttext\&pid=S0080-62342000000400008\&lng= en\&nrm=iso\&tlng=pt

Coletto, M. \& Câmara, S. (2009). Estratégias de coping e percepção da doença em pais de crianças com doença crônica: o contexto do cuidador. Revista Diversitas - Perspectivas em Psicologia, 5(1), 97-110.

Faria, J. (2002). Paciente em longa internação: estratégias de enfrentamento dos familiares (coping). Instituto do Coração do Hospital das Clínicas da Faculdade de Medicina, USP.

Folkman, S. \& Lazarus, R. S. (1984). Stress, appraisal and coping. New York: Springer.

Fortune, D., Richards, H., Kirby, B., McElhone, K. \& Rogers, S. (2003). Psychological diestresse impairs clearance of psoriasis in patients treated with photochemotherapy. Arch Dermatol, 139, 752-6.b.

Fos, M. P., Vale, F. A. C. \& Speciali, J. C. (2005). Influência da escolaridade na avaliação neuropsicológica de idosos. Arq Neuropsiquiatr, 63(1), 119-126. Recuperado em 20 de: janeiro de 2010 de http://www.scielo.br/pdf/ anp/v63n1/23610.pdf

Hayes, B. E. (2001). Medindo a satisfação do cliente. Rio de Janeiro: Qualitymark.

Ismael, S. M. C. (2004). A família do paciente em UTI. Em J.M., Filho \& M., Burd (Org.), Doença e família (pp. 251-257). São Paulo: Casa do Psicólogo.

Kohlsdorf, M. \& Costa Júnior, A. L. (2008). Estratégias de enfrentamento de pais de crianças em tratamento de câncer. Estudos de Psicologia I Campinas, 25(3), 417-429, julho-setembro.

Lucchesi, F., Macedo, P. C. M. \& Marco, M. A. D. (2008). Saúde mental na Unidade de Terapia Intensiva. Revista SBPH, 1, Rio de Janeiro, Jun.
Mackey, W. C. (1985). Fathering behaviors: The dynamics of the man-child bond. New York: Plenum.

Norberg, A. L., Lindbland, F. \& Boman, K. K. (2005). Coping strategies in parents of children with cancer. Social Science \& Medicine, 60(5), 965-975.

Noyes, J. (1999). The impacto of knowing your child is critically ill: a qualitative study of mother's experiences. Journal of Advanced Nursing, 29(2), 427-435.

Nunes, M. A. A. (2004). A ansiedade dos familiares de pacientes internados em Unidade de Terapia Intensiva. Travessia, 6(1), p.209220, Dez.

Oliveira, J. F. (2004). Estratégias de enfrentamento (coping) dos familiares de pacientes internados em Unidade de Terapia Intensiva. Recuperado em 2 de janeiro de 2009 de: http://www.assis.unesp.br/encontrosdepsicologia/ANAIS_DO_XIX_ENCONTRO/45_ Jennifer_de_Fran\%E7a_Oliveira.pdf

Osório, L. C. (1996). Família hoje. Porto Alegre: Artes Médicas.

Papalia, D. E. (2006). Desenvolvimento Humano. Bueno, D. (Trad) $(8$ ed). Porto Alegre: Artmed.

Pestana, M. H. \& Gageiro, J. N. (2005). Análise de dados para ciências sociais: a complementaridade do SPSS (4 ed.). Lisboa: Edições Sílabo.

Pinho, L. B. \& Santos, M. A. (2008). Dialética do cuidado humanizado na UTI: contradições entre o discurso e a prática profissional do enfermeiro. Revista da Escola de Enfermagem da USP, 42(1), São Paulo. Recuperado em 24 de julho de 2009 de: http: / /www.scielo.br/ $\mathrm{pdf} /$ reeusp/v42n1/09.pdf

Rodrigues, M. A., Rosa, J., Moura, M. J. \& Baptista, A. (2000). Ajustamento emocional, 
estratégias de coping e percepção da doença em pais de crianças com doença do foro oncológico. Psicologia, Saúde \& Doenças, 1(1), 61-68.

Romano, B. W. (1997) A família e o adoecer durante a hospitalização. Sociedade de Cardiologia do Estado de São Paulo, 5, 58-62.

Savóia, M. G., Santana, P. R. \& Mejias, N. P. (1996). Adaptação do Inventário de estratégias de coping de Folman e Lazarus para o português. Psicologia USP, 7(1-2), 183-201.

Savóia, M. G. (2000). Instrumentos para avaliação de eventos vitais e de estratégias de enfrentamento (coping) em situações de estresse. In Gorenstein, C., Andrade, L.H. \& Zuardi, A.W. Escalas de avaliação clínica em psiquiatria e psicofarmacologia. São Paulo: Lemos-Editorial.

Senna, D. M. \& Antunes, E. H. (2004). Abordagem da família: a criança, o adolescente e o idoso no contexto de família. Manual de condutas médicas. Recuperado em 24 de janeiro de 2010 de: www.ids-saude.org.br/medicina.

Shimizu, H. E., Ciampone, M. H. T. (2002). As representações sociais dos trabalhadores de enfermagem não enfermeiros (técnicos e auxiliares de enfermagem) sobre o trabalho em Unidade de Terapia Intensiva em um hospital escola. Rev. Esc. Enfermagem USP, 36(2), São Paulo, Junho. Recuperado em 24 de julho de 2011 de: http://www.scielo.br/ $\mathrm{pdf} /$ reeusp/v36n2/v36n2a06.pdf
Silva, M. P. J. (2000). Humanização em Unidade de Terapia Intensiva. In E.A. Cintra, V. M. Nishide \& W.A. Nunes (Orgs.). Assistência de Enfermagem ao Paciente Crítico. São Paulo: Atheneu.

Silva, L. \& Moreno, V. (2004). A Religião e a experiência do sofrimento psíquico: escutando a família. Maringá, 3(2), 161-168, mai/ ago. Recuperado em 20 de janeiro de 2011 de: http://periodicos.uem.br/ojs/index.php/ CiencCuidSaude/article/view/5421/3474

Silva, J. D. T., Muller, M. C. \& Bonamigo, R. R. (2006). Estratégias de Coping e níveis de estresse em pacientes portadores de psoríase. An Bras Dermatol, 81(2), Fev.

Spiegel, S. (1993). Estatística não paramétrica. São Paulo: Editora Macgraw-Hill do Brasil.

Trask, P. C., Paterson, A. G., Trask, C. L., Bares, C. B., Birt, J. \& Maan, C. (2003). Parent and adolescent adjustment to pediatric cancer: associations with coping, social support and family function. Journal of Pediatric Oncology Nursing, 20(1), 36-47.

Wallau, R. A., Guimarães H. P., Falcão, L. F. R., Lopez, R. D., Leal, P. H. L., Senna, A. P. R., Alheira, R. G., Machado, F. R., Amaral, J. L. G. (2006). Qualidade e humanização do atendimento em Medicina Intensiva. Qual a visão dos familiares? Revista Brasileira Intensiva, 18(1). Janeiro/Março. Recuperado em 28 de dezembro de 2011 de: http://www.scielo.br/ pdf/rbti/v18n1/a09v18n1.pdf 